\title{
Minimilho em conserva: avaliação de híbridos
}

\author{
Dorivaldo da Silva RAUPP ${ }^{1}$, José Raulindo GARDINGO², Lirian Ribeiro MORENO², \\ João Paulo Monteiro HOFFMAN, Rodrigo Rodrigues MATIELLO, Aurélio Vinicius BORSATO
}

\section{RESUMO}

O minimilho, uma espiga imatura ainda não fertilizada, vem ganhando importância no Brasil para o consumo como conserva, principalmente por ser agradável e apresentar baixo valor calórico. A pesquisa se propôs avaliar a qualidade das conservas de quatro híbridos; determinar a composição nutricional destes híbridos; e determinar o rendimento de minimilho para a produção de conserva. Os procedimentos de acidificação aplicados durante o processamento, essencial para a qualidade dessas conservas, resultaram em produtos seguros para o consumo. Os provadores preferiram a conserva de minimilho mais ácida, apresentando um valor de $\mathrm{pH}$ projetado para o equilíbrio de 3,9 ao invés de 4,2, bem como, a conserva contendo a salmoura de 4,0\%, p/v, de sal. As conservas dos híbridos DKB 214, P 3021, AG 6018 e DKB 215 não diferiram estatisticamente quanto ao paladar. As composições nutricionais desses híbridos foram similares e confirmaram se tratar de um produto de pouco valor calórico, apresentando concentraçôes porcentuais baixas de carboidratos digeríveis mais proteínas $(6,87-7,21 \%)$ e insignificante de lipídeo $(<$ $0,30 \%)$. Considerando o rendimento em massa média de minimilho sem palha em relação à matéria-prima com palha, o híbrido P 3021 foi o recomendado, pois, apresentou $25,90 \%$ a mais em relação ao híbrido de menor rendimento AG 6018.

PALAVRAS-CHAVE: Zea mays, conservas de minimilho, agroindústria, alimento funcional, composição nutricional.

\section{Processing of canned baby corn: assessment of cultivars}

\section{ABSTRACT}

Baby corn, immature corn-cob yet fertilized, has become important for the canning in Brazil, because it is specially pleasant and low-calories. This research proposed to evaluate the quality of canned baby corn from four cultivars; determine the nutritional compositions of these cultivars; and determine the baby corn yield for canning. The acidification procedures used in processing resulted in a product safe for consumption. The tasters preferred the canned baby corn with highest acidity, which had an estimated $\mathrm{pH} 3.9$ for stabilization, instead of 4.2 and canned with $4.0 \%$ brine. The canned of the cv. DKB 214, P 3021, AG 6018 and DKB 215 were considered equally palatable by the tasters. The nutritional compositions of the four cultivars were similar and these were low-calories because they had law-concentration in both the carbohydrate and the protein, and the lipid was insignificant (lower than $0.30 \%$ ). Thus, considering the yield in baby corn for the canned, the cv. P 3021 was recommended, because it had a yield of 25.90\% higher than the cv AG 6018, which had the lower.

KEY-WORDS: Zea mays, baby corn canned, agroindustry, functional food, nutritional composition.

\footnotetext{
1 Professor Associado Nível A, Doutor, DE, da Universidade Estadual de Ponta Grossa. raupp@uepg.br

2 Universidade Estadual de Ponta Grossa, jrgardin@uepg.br, lirianmoreno@hotmail.com

3 Universidade Federal do Paraná , borsatoav@yahoo.com.br
} 


\section{INTRODUÇÃO}

O minimilho, também conhecido como "baby corn", é o nome dado à espiga de milho jovem contendo os estiloestigmas de até $3 \mathrm{~cm}$, em desenvolvimento e não fertilizada ou ao sabugo jovem da espiga de uma planta de milho. Dentre as várias formas atualmente disponíveis para o consumo, visando o preparo de pratos frios, sopas, cozidos e para sucos, estão: (a) o minimilho in natura; (b) os produtos processados pelas indústrias alimentícias na forma de conservas acidificadas; e (c) os picles caseiros. Assim, com o advento da indústria de conservas de minimilho, essa matéria-prima alimentícia tornou-se gradualmente importante, apresentando um crescimento na sua área de cultivo (Aekatasanawan, 2001; Miles e Zens, 2000).

As plantas são semelhantes às de milho comum e não são, como poderia ser assumido, plantas anãs. Várias cultivares de milhos especiais têm sido avaliadas, mas, cultivares de milho comum têm sido utilizadas para a produção de minimilho, tanto para o comércio in natura como o de conservas (Miles e Zens, 2000). No Brasil, diferentes cultivares de milho têm sido avaliadas com o intuito de identificar aquelas mais adaptadas às condições tropicais (Almeida et al., 2005; Carvalho, Pinho \& Pereira Filho, 2002; Pereira Filho, Gama \& Cruz, 1998; Pinho et al., 2003; Rodrigues, Silva \& Seizo, 2004).

Pinho et al. (2003) determinaram a composição nutricional centesimal de oito cultivares de minimilhos e encontraram os seguintes resultados: umidade, 90,22 a 94,47\%; minerais (cinzas), 0,16 a 0,29\%; proteína, 0,86 a 1,53\%; lipídeo (extrato etéreo), 0,09 a 0,19\%; fibra bruta (método não enzimático), 0,28 a $0,54 \%$; carboidrato (por diferença porcentual), 4,12 a 7,23\%. Também, foram determinados, em $100 \mathrm{~g}$ de minimilho, em média: $86 \mathrm{mg}$ de fósforo; $0,1 \mathrm{mg}$ de ferro; $64 \mathrm{UA}$ de vitamina A; $0,05 \mathrm{mg}$ de tiamina; $0,8 \mathrm{mg}$ de riboflavina; $11 \mathrm{mg}$ de ácido ascórbico; e $0,3 \mathrm{mg}$ de niacina.

As informações estatísticas sobre a produção e o consumo são limitadas porque muitos países produtores negligenciam ou não possuem essas informações. Segundo Pereira Filho, Gama \& Cruz (1998) bem como Miles e Zenz (2000), o minimilho é muito consumido no continente asiático como hortaliça e representa uma atividade econômica significativa em vários continentes, em países tais como Tailândia, Sri Lanka, Taiwan, China, Zimbabwe, Zâmbia e Indonésia, bem como os da América Central, como Nicarágua, Costa Rica, Guatemala e Honduras, que são os exportadores mais conhecidos.

A Tailândia é um dos principais países produtores e o maior exportador. Em 2000, a sua exportação de minimilho enlatado foi de 55.000 toneladas, correspondente a cerca de 42 milhōes de dólares. Desses, 42,8 \% foram exportados para os EUA, $8,9 \%$ para a Austrália e 8,9 \% para o Japão. A exportação de minimilho in natura representa menos de $10 \%$ do produto industrializado. Em 2000, das 4.200 toneladas exportadas pela Tailândia, que equivalem a 4,3 milhões de dólares, 50,7 $\%$ foram exportadas para a Malásia, 25,1 \% para os Países Baixos, 7,3 \% para o Japão e apenas 2,3 \% para os EUA. No Brasil, a produção ainda é inexpressiva, não existindo relato de exportação, ao contrário, continuamos importando minimilho em conserva para o abastecimento de um mercado interno em franca expansão (Aekatasanawan, 2001; Almeida et al., 2005; Miles e Zenz, 2000; Pereira Filho, Gama \& Cruz, 1998).

A aparência da espiga é de suma importância para o consumidor, razão porque é comum na produção de conservas o seu envase em vidro transparente para permitir que o consumidor aprecie características como coloração, formato, tamanho e diâmetro. As espigas devem apresentar os seguintes padrōes comerciais: coloração de branco-pérola a amarelo-claro; forma cilíndrica com ovários pequenos em fileiras uniformes e simétricas; diâmetro de 10 a $18 \mathrm{~mm}$; comprimento de 40 a $120 \mathrm{~mm}$. A colheita deve ser realizada pela manhã, quando a umidade das espigas é mais alta e a temperatura ambiente mais baixa, favorecendo, assim, a manutenção da qualidade da matéria-prima. O ponto ideal de colheita é quando as espigas estão com dois a três dias de exposição dos estilos-estigma. Geralmente, são efetuadas de duas a três colheitas por planta, dependendo da cultivar e da época de semeadura. As espigas devem ser conservadas em local fresco e arejado, o que promove menor perda de água, impedindo a fermentação e a conseqüente depreciação, sendo mais recomendado o armazenamento em câmaras frias, com umidade relativa em torno de $90 \%$ e temperatura de $5^{\circ}$ a $10^{\circ}$ C (Aekatasanawan, 2001; Miles e Zenz, 2000; Pereira Filho e Cruz, 2001; Pereira Filho, Gama \& Cruz, 1998; Pinho et al., 2003; Rodrigues, Silva \& Seizo, 2004).

Minimilho minimamente processado, acondicionado em bandejas de poliestireno (PS) e envolvido com filme plástico esticável de policloreto de vinila (PVC), apresentando espessura de $20 \mu \mathrm{m}$ e autoadesivo, foi armazenado em câmera fria regulada em $5 \pm 1{ }^{\circ} \mathrm{C}$ e $90 \pm 1 \%$ de UR (Reis et al., 2005). Os minimilhos, após sanificação, foram tratados durante cinco minutos com água destilada, com solução aquosa de lactato de cálcio (1\%) ou com solução aquosa de ácido ascórbico (1\%). Segundo os autores, o produto tratado com lactato de cálcio ou ácido ascórbico manteve sua qualidade quanto à aparência e à firmeza durante 12 dias de armazenamento.

O processamento de conservas acidificadas seguras ao consumo humano requer a aplicação conjunta de procedimentos de tratamento térmico e acidificação. Um procedimento de acidificação bem sucedido deve resultar em um $\mathrm{pH}$ no produto abaixo ou igual a 4,5. Quando, 
durante o processamento dessas conservas, as características do produto permanecem favoráveis ao desenvolvimento do Clostridium botulinum, como $\mathrm{pH}$ superior a 4,5 e microambiente da embalagem anaeróbio, os esporos dessa bactéria termo-resistentes ao tratamento térmico aplicado podem se desenvolver para as formas vegetativas e produzirem uma toxina que causa a síndrome conhecida como botulismo, a qual, não raramente, pode resultar em óbito para o consumidor que ingerir tal produto alimentício (Brimelow e Vadehra, 1992; Franco e Landgraf, 1996; Paschoalino, 1994/1997; Raupp, 2004).

A conserva de minimilho, apesar de já conhecida por alguns apreciadores de milho, no Brasil há carência de informações tanto com relação à recomendação de cultivar quanto de protocolos para o processamento de tais conservas. A necessidade e a importância de se ampliar os conhecimentos a respeito dessa temática motivaram a elaboração desta pesquisa. O minimilho, a semelhança do que já ocorre com o milho verde, se constitui em outra alternativa para o produtor, que poderá comercializá-lo na forma de conserva, disponibilizando, com isso, um novo produto para o consumidor que aprecia o milho, bem como agrega valor à produção. Assim, a pesquisa se propôs: (a) avaliar a qualidade das conservas de quatro híbridos (DKB 214, P 3021, AG 6018, DKB 215); (b) determinar a composição nutricional destes híbridos; (c) determinar o rendimento de minimilho para a produção de conserva.

\section{MATERIAL E MÉTODOS}

As matérias-primas, espigas de minimilho de híbridos destinados à produção de grãos, todos precoces, foram semeadas (densidade de 160 mil plantas/hectare) em 26 de janeiro de 2005, na Fazenda Escola Capão da Onça, em Ponta Grossa-PR. Foram utilizados os híbridos recomendados regionalmente AG 6018, DKB 214, DKB 215 e P 3021.

As espigas foram colhidas, a cada três dias, quando os estilo-estigmas estavam de dois a três dias de exposição, ponto recomendado para minimilho em conserva. Para a determinação do diâmetro, comprimento e massa, com e sem palha, foi usada uma amostragem representada por 12 espigas, as quais foram coletadas ao acaso em cada parcela.

No laboratório de processamento, as espigas do minimilho foram descascadas, limpas e selecionadas quanto ao comprimento, o qual não ultrapassou a altura máxima de envase da embalagem, por conseguinte até $10,5 \mathrm{~cm}$, para resultar em aparência agradável na embalagem. Uma massa média de $300 \mathrm{~g}$ foi colocada em cada recipiente de vidro, seguida da adição de salmoura acidificada e do tratamento térmico em água em ebulição por 45 minutos. O resfriamento foi feito usando água à temperatura ambiente.
Foi determinada, previamente, a concentração de sal (cloreto de sódio) da salmoura bem como o pH a serem usados para o processamento das conservas de minimilho das quatro cultivares. Foram testadas três salmouras contendo concentraçōes de sal $(\mathrm{p} / \mathrm{v})$ iguais a $3,5 \%, 4,0 \%$ ou $4,5 \%$, bem como dois valores de $\mathrm{pH}, 4,2$ ou 3,9 , ambos considerados seguros segundo as boas práticas de fabricação para conservas acidificadas (Bellegard et al., 2005; Gomes et al., 2006; Paschoalino, 1994/1997; Raupp et al., 2004). A salmoura $(4,0 \%)$ foi acidificada com ácido cítrico para resultar, depois de atingido o equilíbrio da conserva do híbrido P 3021, pH igual a 3,9 ou 4,2, valores praticados por Bellegard et al. (2005) para a produção de conservas de palmito foliar e por Gomes et al. (2006) para a produção de conservas de palmito caulinar. Para a escolha da melhor salmoura, também foi usado o híbrido P 3021.

O procedimento de acidificação da conserva durante o processamento permitiu abaixar o $\mathrm{pH}$ da matéria-prima (in natura) até o $\mathrm{pH}$ projetado para o equilíbrio $(4,2$ ou 3,9). O agente acidulante foi o ácido cítrico, que se caracteriza por ser um dos ácidos orgânicos mais difundidos na natureza e de aplicação na indústria de alimentos. Para conhecer a quantidade de ácido cítrico da salmoura foi aplicado procedimento de titulação, usando uma solução de ácido cítrico a $2 \% \mathrm{p} / \mathrm{v}$, numa amostra de 50,0 g de minimilho até abaixar o $\mathrm{pH}$ para 4,2 ou 3,9. E, por cálculo foi determinada a massa de ácido cítrico a ser acrescentada na salmoura, levando em conta a massa média de minimilho da embalagem.

Os produtos obtidos foram avaliados (cinco a seis meses após o processamento) quanto ao grau de satisfação, com relação ao paladar, que produziram em provadores não treinados, os quais eram consumidores habituais de produtos de conservas acidificadas. $\mathrm{O}$ provador atribuiu uma pontuação ao paladar do produto degustado, usando a escala hedônica verbal apresentada na Figura 1, a qual foi sugerida por Anzaldúa-Morales (1994), tendo por limite mínimo da escala a descrição "desgostei muitíssimo", pontuação= 1 , e, por limite máximo a descrição "gostei muitíssimo", pontuação $=9$. Por questão de segurança, as conservas de minimilho foram avaliadas quanto ao grau de acidez antes da avaliação sensorial, pois, segundo a literatura (Paschoalino, 1994/1997; Raupp, 2004) a conserva está apropriada ao consumo quando apresentar valor de $\mathrm{pH}$ igual ou abaixo de 4,5. Participaram da avaliação 145, 170 e 192 provadores para as conservas (tratamentos) de diferentes $\mathrm{pH}$, de salmouras e de cultivares, respectivamente. Os dados foram analisados através da análise de variância e as médias de tratamentos foram comparadas pelo teste de Tukey $(P<0,05)$. 
INDIQUE $O$ QUANTO GOSTOU OU DESGOSTOU DOS PRODUTOS APRESENTADOS, SEGUNDO A SEGUINTE ESCALA:

\begin{tabular}{|l|l|}
\hline 1 & Desgostei muitíssimo \\
2 & Desgostei muito \\
3 & Desgostei \\
4 & Desgostei ligeiramente \\
5 & Nem gostei e nem desgostei \\
6 & Gostei ligeiramente \\
7 & Gostei \\
8 & Gostei muito \\
9 & Gostei muitíssimo \\
\hline
\end{tabular}

SENSORIAL DE MINIMILHO EM CONSERVA - PH DIFERENTE

\begin{tabular}{|c|c|}
\hline \multicolumn{2}{|c|}{ Paladar } \\
\hline Amostra & Amostra \\
\hline
\end{tabular}

SENSORIAL DE MINIMILHO EM CONSERVA - SALMOURA DIFERENTE

\begin{tabular}{|c|c|c|}
\hline \multicolumn{3}{|c|}{ Paladar } \\
\hline Amostra & Amostra & Amostra \\
\hline
\end{tabular}

SENSORIAL DE MINIMILHO EM CONSERVA - CULTIVAR DIFERENTE

\begin{tabular}{|c|c|c|c|}
\hline \multicolumn{4}{|c|}{ Paladar } \\
\hline Amostra & Amostra & Amostra & Amostra \\
\hline
\end{tabular}

Figura 1 - Modelo de ficha usada na avaliação sensorial. (a amostra foi codificada, usando número de três dígitos)

Uma amostra de quinze unidades de minimilho da conserva de cada uma das quatro cultivares foi, depois de triturada até obtenção de uma polpa homogênea, usada para determinara composição nutricional da cultivar (cinco a seis meses após o processamento), usando os procedimentos contidos nas Normas Analíticas do Instituto Adolfo Lutz (1985). Com exceção da fibra alimentar, as demais análises foram feitas em triplicata. A umidade e as cinzas (total de minerais), foram determinadas, respectivamente, em estufa regulada em $80^{\circ} \mathrm{C}$ e em forno mufla regulado em $550^{\circ} \mathrm{C}$, até obter peso constante. Os lipídeos foram determinados através de extração com solvente hexano no aparelho de Soxhlet. As proteínas, usando o método de micro-Kjeldahl, o qual determinou o nitrogênio da amostra e a conversão para proteína foi obtida por cálculo usando o fator 6,25. A fibra alimentar foi determinada, em quadruplicata, pelo método de Prosky et al. (1988) com modificações para adaptação às condiçōes de trabalho do laboratório. O método consistiu no uso de cerca de $2 \mathrm{~g}$ de amostra, bem como das enzimas -amilase (thermamyl), protease e amiloglucosidase. O material resistente à hidrólise, depois de filtrado, foi secado em estufa regulada em $70^{\circ} \mathrm{C}$ até peso constante. A proteína e os minerais que permaneceram neste resíduo fibroso foram quantificados analiticamente e os dados obtidos foram subtraídos do peso seco do resíduo fibroso bruto. Os açúcares solúveis redutores e os não-redutores foram também determinados, usando o método de Somogyi (1945). Os resultados das análises da composição nutricional foram expressos em porcentagens.

\section{RESULTADOS E DISCUSSÃO}

As espigas de minimilho dos quatro híbridos (AG 6018, DKB 214, DKB 215, P 3021) apresentaram coloração amarelo-claro, formato cilíndrico, diâmetro de 14,2 a $15,1 \mathrm{~mm}$, comprimento de 80,7 a $101,1 \mathrm{~mm}$ e massa 8,7 a 10,9 g (Tabela 1). Estas características, as quais são consideradas pelos consumidores como atributos de qualidade (Aekatasanawan, 2001; Miles e Zenz, 2000; Pereira Filho e Cruz, 2001; Pereira Filho, Gama \& Cruz, 1998; Pinho et al., 2003; Rodrigues, Silva e Seizo, 2004), foram de acordo com os padrōes comerciais que exigem um formato cilíndrico, coloração variando de branco-pérola ao amarelo-claro, de 10 a $18 \mathrm{~mm}$ de diâmetro e de 40 a $120 \mathrm{~mm}$ de comprimento. Destas características, a coloração e o formato são pouco influenciadas pelo ambiente (Pereira Filho e Cruz, 2001).

Os híbridos de milho não apresentaram diferença significativa para o diâmetro da matéria-prima, mas, com relação ao comprimento, o híbrido DKB 214 foi o que apresentou espiga mais longa (Tabela 1), por conseguinte, exige coletas mais freqüentes para resultar em produto de melhor qualidade. Os híbridos DKB 214 e P 3021 apresentaram maior massa enquanto que o híbrido AG 6018 a menor, não havendo diferença destes em relação ao DKB 215.

Os rendimentos em massa média do minimilho sem palha em relação à matéria-prima com palha foram de $24,59 \%$, $27,53 \%, 20,40 \%$ e $23,70 \%$ para os híbridos DKB 214, P 3021, AG 6018 e DKB 215, respectivamente, valores estes superiores aos relatados por Aekatasanawan (2001). Considerando a importância do rendimento para a conserva, um item exigido pela indústria, o híbrido $\mathrm{P} 3021$ foi o recomendado, pois, apresentou $25,90 \%$ a mais em relação ao híbrido de menor rendimento AG 6018.

Tabela 1 - Dados médios* de diâmetro, comprimento e massa de espigas de minimilho de quatro híbridos. Ponta Grossa, 2005.

\begin{tabular}{|c|c|c|c|c|c|c|}
\hline \multirow[b]{2}{*}{ Híbrido } & \multicolumn{2}{|c|}{ Diâmetro (mm) } & \multicolumn{2}{|c|}{ Comprimento (mm) } & \multicolumn{2}{|c|}{ Massa $(\mathrm{g})$} \\
\hline & $\begin{array}{l}\text { com } \\
\text { palha }\end{array}$ & $\begin{array}{l}\text { sem } \\
\text { palha }\end{array}$ & $\begin{array}{l}\text { com } \\
\text { palha }\end{array}$ & $\begin{array}{l}\text { sem } \\
\text { palha }\end{array}$ & $\begin{array}{l}\text { com } \\
\text { palha }\end{array}$ & $\begin{array}{l}\text { sem } \\
\text { palha }\end{array}$ \\
\hline DKB 214 & $23,1 \mathrm{~A}$ & $15,1 \mathrm{~A}$ & $196,4 \mathrm{AB}$ & $101,1 \mathrm{~A}$ & $42,7 \mathrm{~A}$ & $10,5 \mathrm{~A}$ \\
\hline P 3021 & $22,1 \mathrm{~A}$ & $14,6 \mathrm{~A}$ & 191,2 B & $85,8 \mathrm{~B}$ & $39,6 \mathrm{~A}$ & $10,9 \mathrm{~A}$ \\
\hline AG 6018 & $22,5 \mathrm{~A}$ & $14,3 \mathrm{~A}$ & $201,7 \mathrm{~A}$ & 80,7 B & $42,6 \mathrm{~A}$ & $8,7 \mathrm{~B}$ \\
\hline DKB 215 & $22,1 \mathrm{~A}$ & $14,2 \mathrm{~A}$ & $197,4 \mathrm{AB}$ & $83,9 \mathrm{~B}$ & $40,5 \mathrm{~A}$ & $9,6 \mathrm{AB}$ \\
\hline
\end{tabular}

* valores seguidos da mesma letra na coluna não diferem entre si a 5 \% de probabilidade pelo teste de Tukey.

$\mathrm{O}$ minimilho, o qual tem sido recentemente estimulado, no Brasil, para uso como alimento de diversas maneiras, tanto em saladas como degustação na forma de aperitivo, bem 
como fazendo parte de pratos preparados, tem a vantagem de ser uma hortaliça de baixo valor calórico, como o palmito (Raupp et al., 2004). As composiçôes nutricionais apresentadas na Tabela 2 mostram as concentraçôes porcentuais dos nutrientes das conservas de minimilho dos quatro híbridos avaliados nesta pesquisa: água (como umidade), 90,5090,80\%; minerais (como cinzas), 1,90-2,00\%; lipídeo, 0,17-0,24\%; proteína, 1,20-1,56\%; fibra alimentar, que considera o carboidrato não digerível pelos sucos digestivos, 0,23-0,28 \%; o total de carboidrato digerível, 5,52-5,59\%. O carboidrato solúvel, determinado como açúcar redutor e não-redutor, representaram 1,90-2,05 \% e 0,00-0,23 \%, respectivamente.

Além de apresentar alta quantidade de água (cerca de 90 $\%$ ), com relação aos nutrientes calóricos, estes minimilhos possuem, como esperado, uma quantidade baixa de carboidrato digerível mais proteína $(6,87-7,21 \%)$ e insignificante de lipídeo, menos de 0,30 \% (Tabela 2).

Em pesquisa realizada por Pinho et al. (2003), em que foram avaliadas outras cultivares, num total de oito, os resultados obtidos para as composiçóes nutricionais foram similares aos da pesquisa atual, com exceção do total de minerais (cinzas). Os valores porcentuais bem mais altos determinados, na pesquisa atual, para o total de minerais (cinzas) os quais variaram de 1,90 a 2,00 \%, contrastando com os determinados por Pinho et al. (2003), de 0,16 a 0,29 $\%$, em parte podem ser explicados pela exposição ao sal da salmoura, pois, na pesquisa atual a composição nutricional foi determinada nos minimilhos das conservas.

Os minimilhos das cultivares avaliadas na pesquisa atual apresentaram para os açúcares solúveis totais (redutor + não redutor) teores menores, mínimo de $1,90 \%$ e máximo de 2,20 $\%$ (Tabela 2), que aquele determinado por Reis et al. (2005) no minimilho da cultivar DKB 929, que foi de 2,93\%.

Tabela 2 - Composição nutricional (\%, p/p) de minimilho em conservas, de quatro híbridos. Ponta Grossa-PR, 2005.

\begin{tabular}{|c|c|c|c|c|}
\hline \multirow{2}{*}{ Constituintes } & \multicolumn{4}{|c|}{ Cultivares de milho } \\
\hline & DKB 214 & P 3021 & AG 6018 & DKB 215 \\
\hline Umidade & $90,80(0,53)$ & $90,50(0,62)$ & $90,70(0,43)$ & $90,30(0,53)$ \\
\hline Minerais ${ }^{1}$ & $1,90(0,03)$ & $1,90(0,09)$ & $1,98(0,14)$ & $2,00(0,11)$ \\
\hline Lipídeo & $0,18(0,03)$ & $0,24(0,04)$ & $0,17(0,03)$ & $0,23(0,03)$ \\
\hline Proteína ${ }^{2}$ & $1,20(0,03)$ & $1,56(0,04)$ & $1,35(0,04)$ & $1,53(0,02)$ \\
\hline Fibra alimentar ${ }^{3}$ & $0,23(0,05)$ & $0,23(0,03)$ & $0,28(0,06)$ & $0,26(0,04)$ \\
\hline $\begin{array}{l}\text { Carboidrato } \\
\text { digerível total }{ }^{4}\end{array}$ & $5,69(0,57)$ & $5,57(0,58)$ & $5,52(0,31)$ & $5,68(0,56)$ \\
\hline $\begin{array}{l}\text { Açúcar solúvel } \\
\text { redutor }^{5}\end{array}$ & $1,90(0,10)$ & $1,90(0,13)$ & $2,05(0,13)$ & $1,97(0,09)$ \\
\hline $\begin{array}{l}\text { Açúcar solúvel } \\
\text { não-redutor }\end{array}$ & $0,20(0,02)$ & $0,00(0,00)$ & $0,05(0,03)$ & $0,23(0,03)$ \\
\hline
\end{tabular}

As conservas de minimilho de todos os tratamentos as quais foram avaliadas sensorialmente (Tabelas 3, 4, 5) apresentaram, no equilíbrio, valores de $\mathrm{pH}$ muito próximos ou iguais, tanto na salmoura quanto no minimilho, ao que foi projetado durante o processamento, isto é, de 4,2 ou 3,9. As conservas que tiveram $\mathrm{pH}$ projetado para 4,2 apresentaram, no equilíbrio, valores de $\mathrm{pH}$ que variaram de 4,1-4,2 para a salmoura e de 4,0-4,1 para o minimilho. E, as que tiveram $\mathrm{pH}$ projetado para 3,9 apresentaram, no equilíbrio, valores de $\mathrm{pH}$ que variaram de 3,85-3,9 para a salmoura e de 3,8-3,9 para o minimilho.

O procedimento de acidificação aplicado foi bem sucedido, pois resultou um $\mathrm{pH}$ no produto abaixo ou igual a 4,5, que éo recomendado pelas boas práticas de fabricação para produtos de conservas acidificadas. A segurança alimentar de conservas acidificadas é obtida combinando-se procedimentos de acidificação e tratamento térmico. A acidificação da conserva permite o uso de um tratamento térmico abrandado, de modo a não danificar a textura agradável do produto e, ainda assim, resultar em conserva segura ao consumo (Paschoalino, 1994/1997; Raupp, 2004).

Em conservas de palmito caulinar de pupunha, também conhecidas por conservas de palmito basal, nas quais ocorre pouca variação do conteúdo de produto entre embalagens, foi recomendado como segurança o uso de um $\mathrm{pH}$ abaixo de 4,3 para a projeção, durante o processamento, da acidez de equilíbrio (Gomes et al., 2006). O palmito caulinar in natura apresentou, segundo Gomes et al. (2006), $\mathrm{pH}$ entre 5,82 e 5,93. Já, para as conservas de palmito foliar de pupunha, também denominadas comumente de conservas de palmito tolete, foi recomendado o uso de $\mathrm{pH} 3,9$ devido principalmente à variação de conteúdo entre embalagens de um mesmo lote processado (Bellegard et al., 2005). O palmito foliar in natura apresentou, segundo Bellegard et al. (2005), $\mathrm{pH}$ entre 5,98 e 6,38.

Quanto ao grau de acidez, os provadores preferiram a conserva de minimilho mais ácida (Tabela 3), àquela processada para apresentar um valor de $\mathrm{pH}$ projetado, para o equilíbrio, de 3,9 ao invés de 4,2. E, com relação à concentração de sal da salmoura, os provadores preferiram as conservas contendo a salmoura de 4,0\%, seguida de 4,5\% e de $3,5 \%$ (Tabela 4 ).

Tabela 3 - Avaliação sensorial quanto ao paladar* de conservas de minimilho produzidas em dois diferentes $\mathrm{pH}$, usando salmoura a $4 \% \mathrm{p} / \mathrm{v}$ e 0 híbrido $\mathrm{P}$ 3021. Ponta Grossa-PR, 2006.

\begin{tabular}{llllll}
\hline Tratamento & Repetição & Soma & Média & Variância & Tukey $^{* *}$ \\
\hline pH 4,2 & 145 & 864,56 & 5,96 & 3,33 & B \\
\hline pH 3,9 & 145 & 994,50 & 6,86 & 2,25 & $\mathrm{~A}$ \\
\hline
\end{tabular}

* total de 145 provadores; ** médias seguidas da mesma letra na coluna não diferem entre si a $5 \%$ de probabilidade pelo teste de Tukey. 
Tabela 4 - Avaliação sensorial quanto ao paladar* de conservas de minimilho produzidas em três diferentes salmouras, usando pH 3,9 e o híbrido P 3021. Ponta Grossa-PR, 2006.

\begin{tabular}{llllll}
\hline Tratamento & Repetição & Soma & Média & Variância & Tukey $^{* *}$ \\
\hline $\begin{array}{l}\text { Salmoura } \\
\text { 3,5\% }\end{array}$ & 170 & 978,66 & 5,76 & 5,92 & C \\
$\begin{array}{l}\text { Salmoura } \\
\text { 4,0\% }\end{array}$ & 170 & 1135,62 & 6,68 & 4,32 & A \\
$\begin{array}{l}\text { Salmoura } \\
\text { 4,5\% }\end{array}$ & 170 & 1070,01 & 6,29 & 4,54 & B \\
\hline
\end{tabular}

* total de 170 provadores; ** médias seguidas da mesma letra na coluna não diferem entre si a $5 \%$ de probabilidade pelo teste de Tukey.

Apesar de a variância ser alta, significando uma dispersão considerável em relação à média, com relação ao $\mathrm{pH}$ das conservas houve por parte dos provadores aprovação (atribuição de pontuação igual ou acima de "gostei”) do produto de $59,31 \%$ para o $\mathrm{pH} 4,2$ e de $82,06 \%$ para o produto apresentando $\mathrm{pH} 3,9$. Em relação ao grau de salinidade, as conservas contendo salmoura de 3,5\%, 4,0 $\%$ ou $4,5 \%$ tiveram aprovação (atribuição de pontuação igual ou acima de "gostei") de 50,00 \%, 66,47 \% ou 55,29 $\%$, respectivamente. Isso mostra que os provadores tiveram maior facilidade para distinguir os produtos quanto ao grau de acidez do que quanto ao grau de salinidade.

Tabela 5 - Avaliação sensorial quanto ao paladar* de conservas de minimilho produzidas a partir de quatro cultivares, usando salmoura a $4 \% \mathrm{p} / \mathrm{v}$ e pH 3,9. Ponta Grossa-PR, 2006.

\begin{tabular}{llllll}
\hline Tratamento & Contagem & Soma & Média & Variância & Tukey $^{* *}$ \\
\hline DKB 214 & 192 & 1242,54 & 6,47 & 1,99 & $\mathrm{~A}$ \\
\hline P 3021 & 192 & 1218,60 & 6,35 & 2,93 & $\mathrm{~A}$ \\
\hline AG 6018 & 192 & 1228,68 & 6,40 & 2,96 & $\mathrm{~A}$ \\
\hline DKB 215 & 192 & 1240,15 & 6,46 & 2,32 & $\mathrm{~A}$ \\
\hline
\end{tabular}

* total de 192 provadores; ${ }^{* \star}$ médias seguidas da mesma letra na coluna não diferem entre si a $5 \%$ de probabilidade pelo teste de Tukey.

A presença de $1,90 \%$ de açúcar solúvel nas espigas do minimilho do híbrido P 3021 (Tabela 2), o qual foi usado para determinação do melhor $\mathrm{pH}$ das conservas, aparentemente deve ter contribuído na escolha dos provadores por uma conserva mais acidificada. $\mathrm{O}$ maior grau de acidez na conserva do Tratamento produzido com pH 3,9 muito provavelmente abrandou a doçura característica da matériaprima proporcionando um sabor/aroma que teve a aprovação dos provadores.

Em pesquisa prévia com conservas de palmito foliar de pupunha (Raupp et al., 2004), cuja matéria-prima apresenta também algum teor de açúcar solúvel, dentre as salmouras testadas as quais continham $3,5 \%, 4,0 \%$ ou $4,5 \% \mathrm{de} \mathrm{sal,} \mathrm{p/v,}$ os provadores não treinados preferiram, quanto ao gosto do palmito, conservas contendo as salmouras de $3,5 \%$ ou $4,0 \%$, não havendo diferença significativa entre estas conservas.

Os produtos de minimilho em conservas dos híbridos não diferiram estatisticamente quanto ao paladar (Tabela 5), quando avaliados por provadores não treinados. As características desses produtos com relação à composição nutricional, por serem muito semelhantes, devem ter sido um dos fatores que contribuiu para tal resultado. Muitos dos provadores fizeram comentários elogiando os produtos de conserva de minimilho que lhes foram apresentados.

\section{CONCLUSÕES}

Os procedimentos de acidificação aplicados durante o processamento das conservas de minimilho resultaram em produtos contendo valores de $\mathrm{pH}$ seguros para o consumo.

Os provadores preferiram a conserva de minimilho mais ácida, a que apresentou um valor de $\mathrm{pH}$ projetado para o equilíbrio de 3,9 ao invés de 4,2, bem como, a conserva contendo a salmoura de $4,0 \%, \mathrm{p} / \mathrm{v}$, de sal.

Os produtos de minimilho em conserva dos híbridos (DKB 214, P 3021, AG 6018, DKB 215) não diferiram estatisticamente quanto ao paladar.

As composições nutricionais dos quatro híbridos foram similares, e confirmaram se tratar de um produto pouco calórico, apresentando concentraçôes porcentuais baixas de carboidrato digerível mais proteína $(6,87-7,21 \%)$ e insignificante de lipídeo (menos de 0,30\%).

Com relação ao rendimento, o híbrido P 3021 foi o recomendado por apresentar $25,90 \%$ a mais de minimilho (sem palha) em relação ao híbrido de menor rendimento AG 6018 .

\section{BIBLIOGRAFIA CITADA}

Aekatasanawan, C. 2001. Baby corn. In: Hallauer, A.R. (ed.). Specialty corns. vol. 2, 2ed. Iowa: CRC Press. cap.9, p.275-292.

Almeida, I.P.C; Silva, P.S.L.; Negreiros, M.Z.; Barbosa, Z. 2005. Baby corn, green ear, and grain yield of corn cultivars. Horticultura Brasileira, 23 (4): 960-964.

Anzaldúa-Morales, A. 1994. La evaluación sensorial de los alimentos en la teoría y la práctica. Zaragoza (España): Editorial Acribia. 198 pp.

Bellegard, C.R.G.; Raupp, D.S.; Chaimsohn, F.P.; Borsato, A.V. 2005. Avaliação de procedimento de acidificação de conservas de palmito foliar de pupunha (Bactris gasipaes). Acta Scientiarum Agronomy, 27 (2): 247-254. 
Brimelow C.; Vadehra, D. 1992 Refrigeración. In: Arthey, D.; Dennis, C. (Eds). Procesado de hortalizas. Zaragoza (Espanha): Editorial Acribia. p.139-173.

Carvalho, G.S.; Pinho, R.G.V.; Pereira Filho, I.A. 2002. Efeito do tipo de cultivar, despendoamento das plantas e da época de semeadura na produção de minimilho. Revista Brasileira de Milho e Sorgo, 1 (3): 47-58.

Franco, B.D.G.M.; Landgraf, M. 1996. Microrganismos patogênicos de importância em alimentos. In: Franco, B.D.G.M.; Landgraf, M. (Eds). Microbiologia dos alimentos. São Paulo: Editora Atheneu. p.33-41.

Gomes, M.; Valle, J.; Raupp, D.S.; Chaimsohn, F.P.; Borsato, A.V. 2006. Processamento de conservas de palmito caulinar de pupunha contendo diferentes graus de acidez. Ciência Agrotecnologia, 30 (3): 569-574.

INSTITUTO ADOLFO LUTZ (IAL). 1985. Normas Analiticas do Instituto Adolfo Lutz: métodos químicos e fisicos para análise de alimentos. São Paulo: IAL. 533pp.

Miles, C.A.; Zenz, L. 2000. Baby corn. In: Farming West of the Cascades. Washington, D.C.: Washington State University. 8pp. (http: //cru. cahe.wsu.edu/cepublications/pnw0532/pnw0532. pdf). Acesso: 22/01/07.

Paschoalino, J.E. 1994. Processamento de hortaliças. Manual Técnico do Instituto de Tecnologia de Alimentos - ITAL, 4: 1-70.

Paschoalino, J.E. 1997. Hortaliças acidificadas em conserva: riscos e cuidados, Informativo Fruthotec do Instituto de Tecnologia de Alimentos - ITAL, 3 (2): 1-3.

Pereira Filho, I.A.; Cruz, J.C. 2001. Manejo cultural do minimilho. Sete Lagoas-MG: Empresa Brasileira de Pesquisa Agropecuária Centro Nacional de Pesquisa de Milho e Sorgo, 1ed.. 4pp.
Pereira Filho, I.A.; Gama, E.E.G.; Cruz, J.C. 1998. Minimilho: efeito de densidade de plantio e cultivares na produção e em algumas características da planta do milho. Comunicado Técnico da Empresa Brasileira de Pesquisa Agropecuária - Centro Nacional de Pesquisa de Milho e Sorgo, 23: 1-6.

Pinho, R.G.V.; Carvalho, G.S.; Rodrigues, V.N.; Pereira, J. 2003. Características físicas e químicas de cultivares de milho para produção de minimilho. Ciência Agrotecnologia, 27 (6): 14191425.

Prosky. L.; Asp, N.G.; Schweizer, T.F.; Devries, J.W.; Furda, I. 1988. Determination of insoluble, soluble and total dietary fiber in foods and food products: interlaboratory study. Journal of the Association of Official Analytical Chemistrs, 71 (5): 1017-1023.

Raupp, D.S. 2004. Higiene e sanidade do produto palmito. Documentos - Embrapa Florestas, 105: 59-66.

Raupp, D.S.; Almeida, F.C.C.; Staron, E.A.; Valle, J.; Borsato, A.V.; Santos, A.F. 2004. Conservas de palmito de pupunha em diferentes salmouras - avaliação senrorial. Publicatio UEPG Ciências Exatas e da Terra, Ciências Agrárias e Engenharia, 10 (1): 27-33.

Reis, K.C.; Pereira, J.; Lima, L.C.O.; Pinho, R.G.V.; Morais, A.R. 2005. Aplicação de lactato de cálcio e ácido ascórbico na conservação de minimilho minimamente processado. Ciência e Agrotecnologia, 29 (2): 338-345.

Rodrigues, L.R.F.; Silva, N.A.M.; Seizo, E. 2004. Avaliação de sete famílias $S_{2}$ prolificas de minimilho para a produção de híbridos. Bragantia, 63 (1): 31-38.

Somogyi, M. 1945. A new reagent for the determination of sugar. The Journal of Biological Chemistry, 160: 61-68.

Rcebido em 29/11/2007

Aceito em 13/03/2008 
ACTA

AMAZONICA

Minimilho em conserva: avaliação de híbridos 